\title{
THE CORROSION RESISTANCE OF ZINC FLAKE COATINGS
}

\author{
Markéta MOŠNIČKOVÁ, Martina NĚMCOVÁ, Markéta PARÁKOVÁ \\ SVUOM Ltd., Prague, Czech Republic, EU, mosnickova@svuom.cz
}

https://doi.org/10.37904/metal.2021.4169

\begin{abstract}
Flake zinc-aluminium coatings are used in industry for decades. They can perform high corrosion resistance according to required accelerated tests, but in the field application the corrosion resistance is reduced due to nonuniform thickness of coating layers. In case the same thickness of coating, the corrosion resistance is affected by composition of coating.
\end{abstract}

Keywords: Flake coating, properties, corrosion resistance, testing methods

\section{INTRODUCTION}

Surface coatings for screws and similar products are assigned to non-metallic and metallic surfaces. So-called galvanically applied coatings or zinc flake (lamella) coatings are generally used to protect metallic surfaces in order to increase corrosion protection. Zinc flake coating is a non-electrolytic coating, which consists of a socalled inorganic basecoat and a topcoat.

Flake zinc-aluminium coatings are used in automotive, aerospace and building industry around whole word for nearly 40 years with different trade names. They are used in wide range of combination of primer zincaluminium layers and coloured or friction inorganic top layers - (Figure 1). Many specifications require a minimum proportion of $70 \%$ zinc and $10 \%$ aluminium, but today, in systems of the latest generation, further alloy components are added in order to further increase corrosion protection and significantly reduce coating corrosion/white rust formation [1]. The high proportion of metallic pigments in platelet form (flakes) and the presence of conductive binders guarantee a very good cathodic protection and classify the layer as an inorganic coating, mainly silane compound (e.g. (3-aminopropyl) triethoxysilane, tetra ethoxysilane, vinyltriethoxysilane, methyltriethoxysilane) and titanate compound (e.g. tetrabutyl titanate).

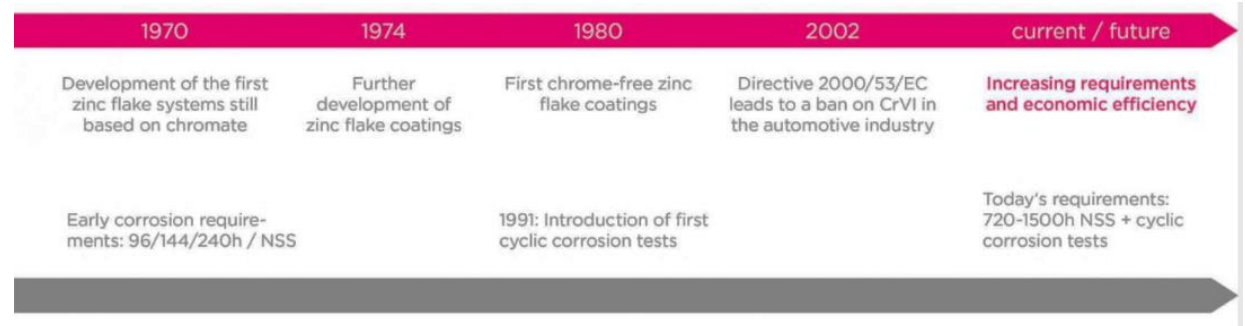

Figure 1 Time development of flake coatings

In the form of single- or multilayers, layer thicknesses of 4 to $8 \mu \mathrm{m}$ have to be obtained - the total thickness is usually $15-25 \mu \mathrm{m}$. The surface coating is free of chromium (VI) and the zinc flakes provide cathodic protection: the less noble zinc 'sacrifices' itself in order to protect the underlying metal. The specifications for zinc flake coatings are defined in international standard ISO 10683 Fasteners - Non-electrolytically applied zinc flake coating systems and also in European standard EN 13858 Corrosion protection of metals. Non-electrolytically applied zinc flake coatings on iron or steel components. ISO 10683 sets out the requirements for zinc flake 
coatings for threaded fasteners and EN 13858 describes the requirements for zinc flake coatings for fasteners with no thread and for other parts as well.

Depending on the area of application, surface technologies also offer different pre-treatments, such as degreasing, sandblasting and phosphating. The process consists on zinc and aluminium lamella flakes dissolved in a solvent base. The combination of different bases and topcoats enables it customization for specific requirements: corrosion resistance improvement, specific colour or friction coefficient with integrated lubricants or applied over the base coat. In order to find the base and top coat solutions that best match each component $[2,3]$.

\section{CORROSION RESISTANCE OF FLAKE COATINGS}

According to ISO 10683 there are four basic zinc flake coating systems as shown in (Figure 2). The coefficient of friction can be adjusted to targeted values ranging from 0.06 to 0.20 with selected topcoats.

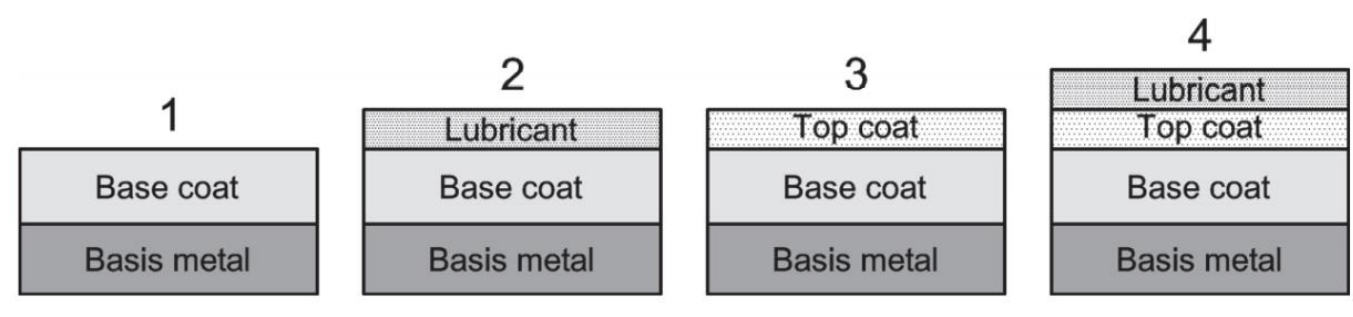

Figure 2 Basic zinc flake coating systems

The characteristic for these types of coating is shape of pigments - (Figure 3). The flat, nearly 2 D shape pigments should be made up horizontally with the metal surface. This arrangement creates longer path for humidity and/or pollution to penetrate through coating layers - excellent barrier protection. The second protective mechanism is cathodic one, because ignoble zinc, as the less noble metal, in the base coat sacrifices itself, corrodes and protects the substrate steel from deteriorating - electrochemical mechanism. In many cases the top layer given passive protection, too. The chromate films are now replaced by ecological accepted ones [4].

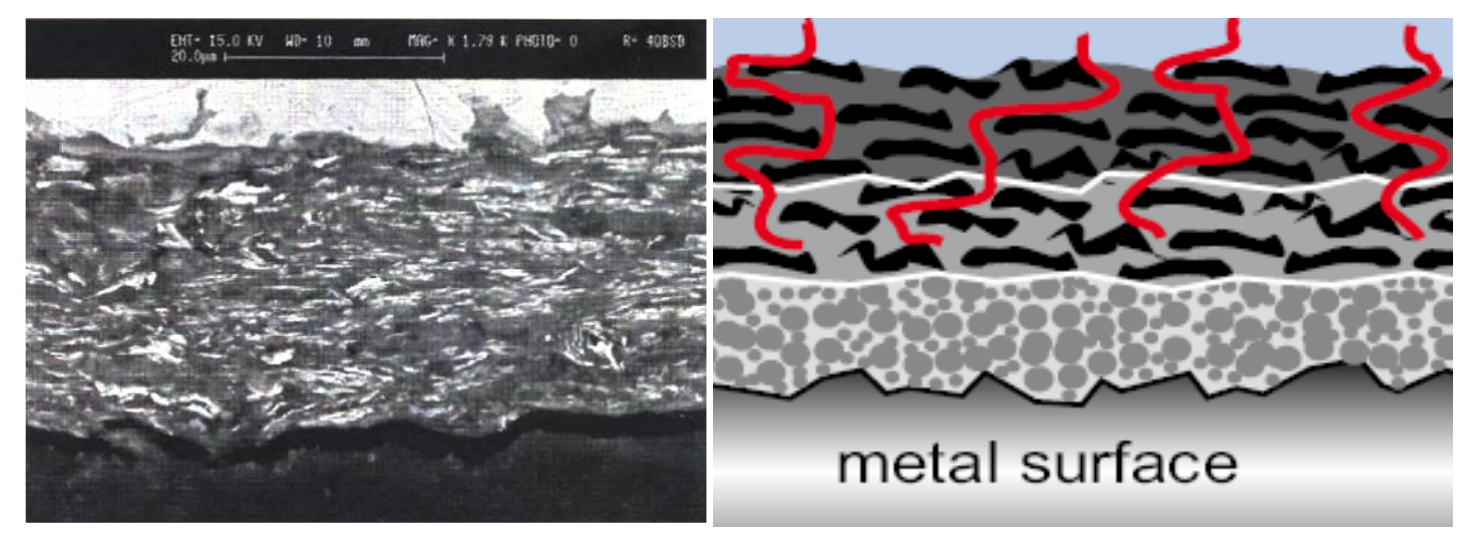

Figure 3 The example of flake coating characteristic structure

Accelerated corrosion tests may indicate lower quality of coating, but their results cannot be used for prediction of service life of corrosion protection given by flake coatings. The ISO 10683 requires corrosion tests to use to evaluate the corrosion resistance of the coating systems by neutral salt spray test (NSS) according to ISO EN 9227 Corrosion tests in artificial atmospheres - Salt spray tests and by sulphur dioxide test (Kesternich test) according to ISO 6988 Metallic and other non organic coatings - Sulfur dioxide test with general condensation 
of moisture. Zinc- and/or aluminium flake coatings obtain very good protection against corrosion, ca 240 - 1 500 hrs in neutral salt spray test, depending on composition and coating thickness - it takes about 100 hours to etch the coating $1 \mu \mathrm{m}$. Accelerated corrosion tests may indicate lower quality of coating, but their results cannot be used for prediction of service life of corrosion protection given by flake coatings.

The sulphur dioxide test is only intended for outdoor building fasteners, but ETA 006 Guideline for European technical approval of systems of mechanically fastened flexible roof waterproofing membranes prescribes this test in duration 15 cycles with $2 \mathrm{~L} \mathrm{SO}_{2}$ concentration.

Some of coating suppliers, mainly for automotive industry, specify also the cyclic tests (CCT) - see Table 1. E.g. CCT according to GM9540P specification consists from $8 \mathrm{hrs}$ exposure to an ambient climate of 40 to $50 \% \mathrm{RH}$ at $25^{\circ} \mathrm{C}$, during which salt solution is sprayed directly on to the test samples 4 times; followed by $8 \mathrm{hrs}$ exposure to a water fog humidity climate of $100 \% \mathrm{RH}$ at $49^{\circ} \mathrm{C}$ and $8 \mathrm{hrs}$ of air drying in a climate of $<30 \% \mathrm{RH}$ at $60^{\circ} \mathrm{C}$. The number of cycle repeats and therefore the test duration is variable.

The duration in all tests is required till the first corrosion of substrate steel occurs.

Table 1 The survey of corrosion resistance requirements for flake coatings

\begin{tabular}{|c|c|c|c|c|c|}
\hline coating & thickness $(\boldsymbol{\mu m})$ & $\begin{array}{c}\text { coating weight } \\
\left(\mathbf{g} \cdot \mathbf{m}^{-2}, \mathbf{m i n}\right)\end{array}$ & NSS (hrs, min) & $\begin{array}{c}\text { Kesternich test } \\
\text { (cycles, min) }\end{array}$ & $\begin{array}{c}\text { CCT - } \\
\text { GM9540P } \\
\text { (cycles, min) }\end{array}$ \\
\hline base layer (silver) & $5-6$ & $20-25$ & 500 & 6 & 80 \\
\hline $\begin{array}{c}\text { multi layer } \\
\text { (silver/black) }\end{array}$ & 10 & $30-36$ & 1000 & 12 & 80 \\
\hline $\begin{array}{c}\text { multi layer + top layer } \\
\text { (silver/black) }\end{array}$ & $6-10$ & $22-25$ & $500-1000$ & $6-12$ & 80 \\
\hline
\end{tabular}

\section{MATERIALS AND METHODS}

The 2 types of coating applied for fasters are tested in the form of steel bars - (Figure 4):

- $\quad$ sample 1 - silver coating, $2 x$ basic layer +3 top layer, total thickness ca $23 \mu \mathrm{m}$,

- $\quad$ sample 2 - black coating, $3 \times$ basic layer $+3 \times$ top layer, total thickness ca $24 \mu \mathrm{m}$.
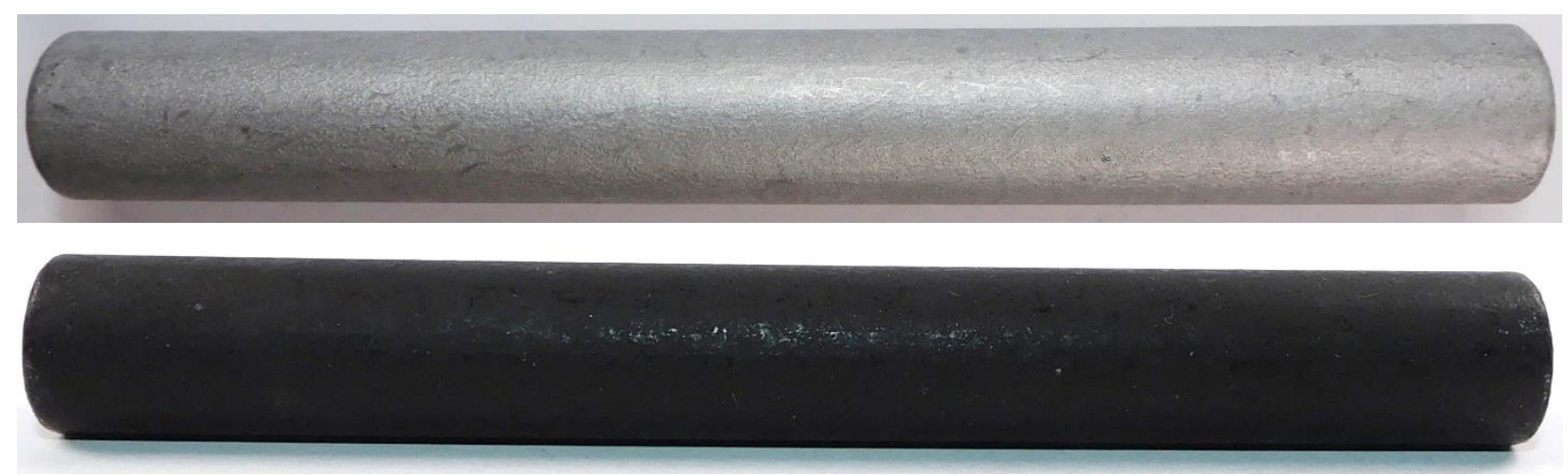

Figure 4 Tested samples

Before corrosion test the metallographic evaluation of coatings was performed with light microscopes 3D Keyence VHX-5000 - (Figure 5). The both coatings' thickness correspond to specification. The characteristic lamellar structure of pigments is evident in coating layers. There are discontinuities in coatings. 

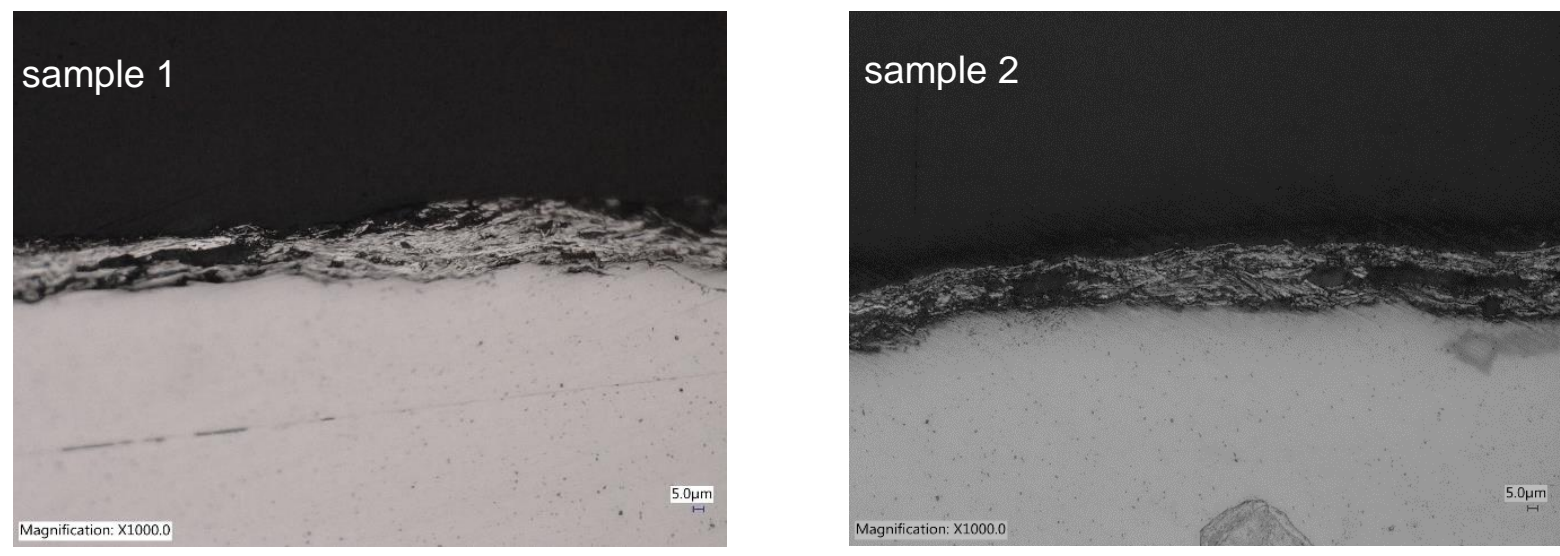

Figure 5 Cross cut of coatings' layers

The corrosion tests were performed by neutral salt spray test and sulphur dioxide test with $2 \mathrm{~L}$ of $\mathrm{SO}_{2}$ dosage. In each test regimes 2 pcs of sample had been exposed. The samples were visually evaluated during the tests to identify the first substrate steel corrosion occurrence - results are given in Table 2 and (Figures 6 and 7 ).

Table 2 Test duration to the $1^{\text {st }}$ corrosion spots of substrate steel

\begin{tabular}{|c|c|c|}
\hline sample & NSS test (hrs) & 2 $\mathbf{~ L ~ S O}_{\mathbf{2}}$ test (cycles) \\
\hline 1 & 144 & 9 \\
\hline 2 & 500 & 8 \\
\hline
\end{tabular}

Salt spray test results - test was finished after 3000 hrs of exposure:

- $\quad$ sample 1 - the first spots of substrate steel corrosion products formed after $144 \mathrm{hrs}$ of exposure; during next exposure the number and size of spots slightly increased, but the significant increasing occurred after 1656 hrs of exposure, when $1 \mathrm{pc}$ was withdrawn for detailed evaluation - (Figure 6);

- $\quad$ sample 2 - on the samples the white corrosion products of zinc gradually formed and spread; after ca 500 hrs the white corrosion products covered $30 \%$ sample's area; the first spots of substrate steel corrosion products formed after $720 \mathrm{hrs}$ of exposure, but the significant increasing occurred after 1656 hrs of exposure, when $1 \mathrm{pc}$ was withdrawn for detailed evaluation - (Figure 6);

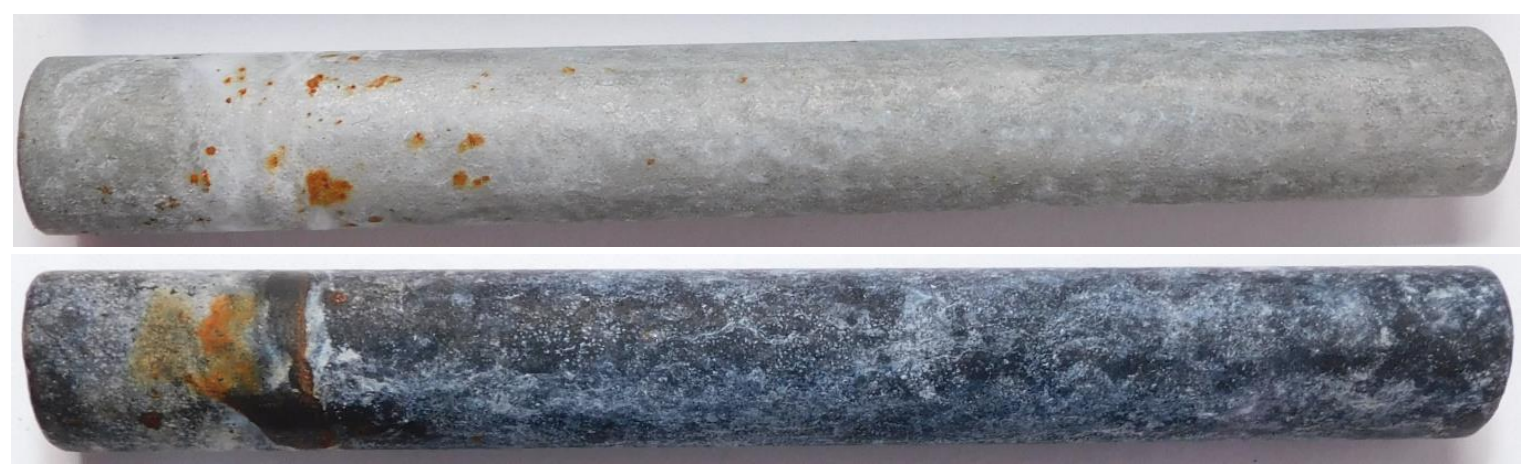

Figure 6 Tested samples after 1656 hrs in NSS test

Sulphur dioxide test results - test was finished after 15 cycles of exposure:

- $\quad$ sample 1 - after 2 cycles the white zinc corrosion products occurred on the sample surface; the first spots of substrate steel corrosion products formed after 9 cycles of exposure - (Figure 7);

- $\quad$ sample 2 - the first spots of substrate steel corrosion products formed after 8 cycles of exposure on the edge of samples - (Figure 7). 


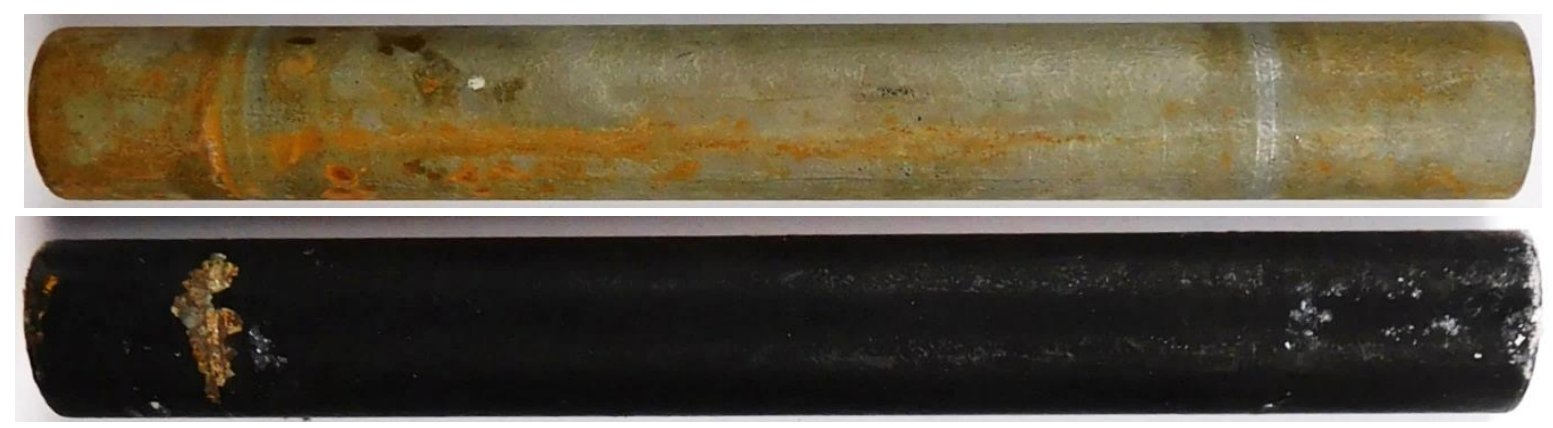

Figure 7 Tested samples after 15 cycles in $\mathrm{SO}_{2}$ test

The details of corrosion attack of layers are given on (Figure 8) after both corrosion tests. There are evident different mechanisms of corrosion attack. In NSS test the coatings degraded from top of coating layer so even for the sample 2 with higher corrosion resistance the corrosion of zinc pigment occurred and presented itself in the form of white layer of zinc corrosion product. The reduction and discontinuities of top part of coating is evident. In $\mathrm{SO}_{2}$ test the coating stayed with change. The sample 1 coating was under-corroded in the both tests, but in NSS test the coating was not broken as it happens in $\mathrm{SO}_{2}$ test. In case the same thickness the composition of coating is significant for corrosion resistance of zinc flake coatings.
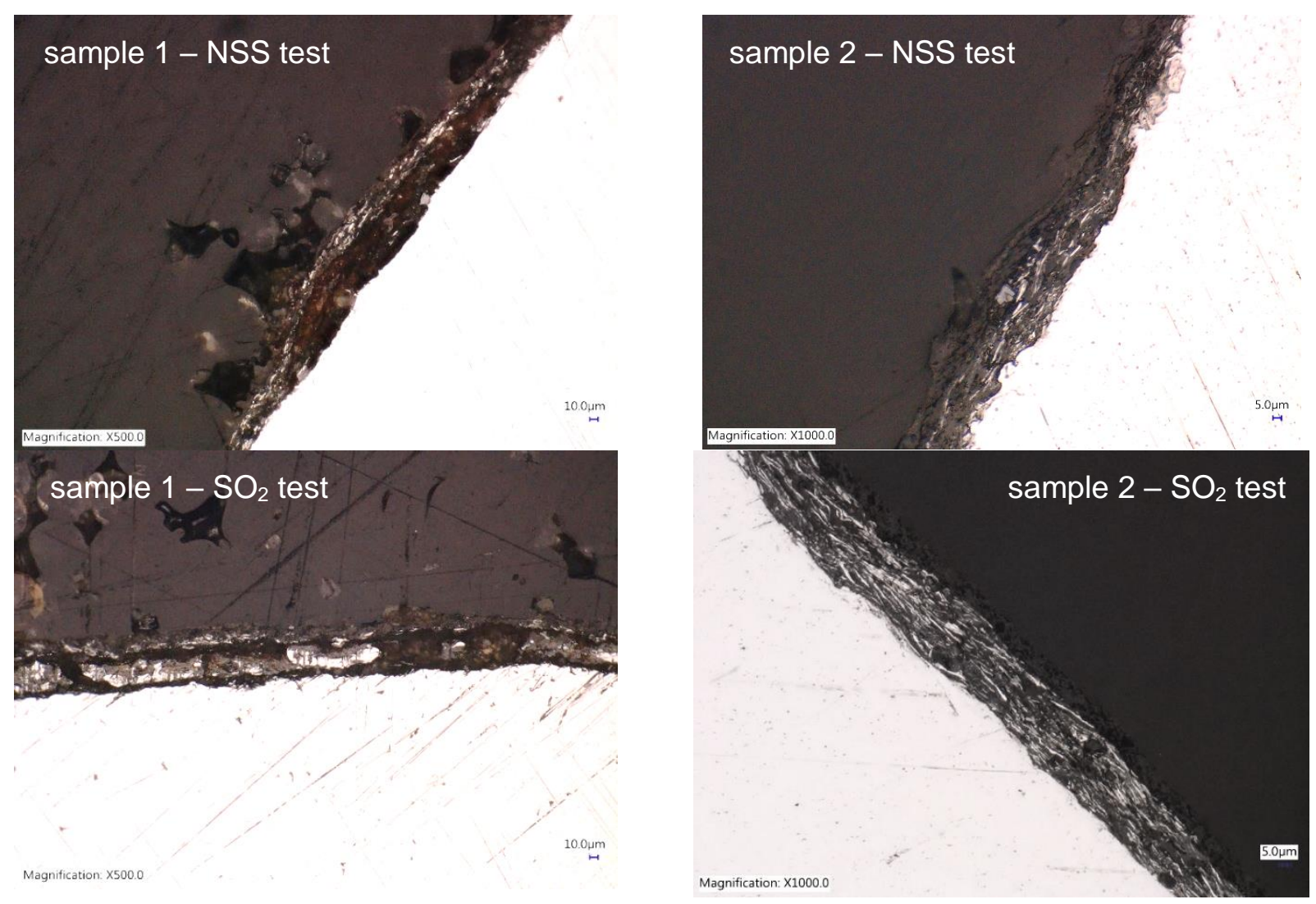

Figure 8 Cross cut of coatings' layers after exposure in corrosion tests

\section{CONCLUSION}

Zinc sacrificial corrosion protection is the main corrosion resistance mechanism of the zinc/aluminium flake coating film. The accelerated corrosion tests are used to check the coating quality for fasteners, washers, nuts, screws and many other joining parts for automotive, building and other industry [5]. 
The field application of fasters with these types of coating showed premature failure due to non-uniform coating thickness distribution - (Figure 9). This typical case study of screws and nuts used for photovoltaic panels demonstrated significant substrate steel corrosion after 1 year exposure in service in open atmosphere. The cross section shows the extremely non-uniform coating thickness and corrosion attack started at such areas. This type of defect is typical for all coatings applied in barrel technology. The same problem occurred for washers used for 1 year on dam Orlik ship lift.
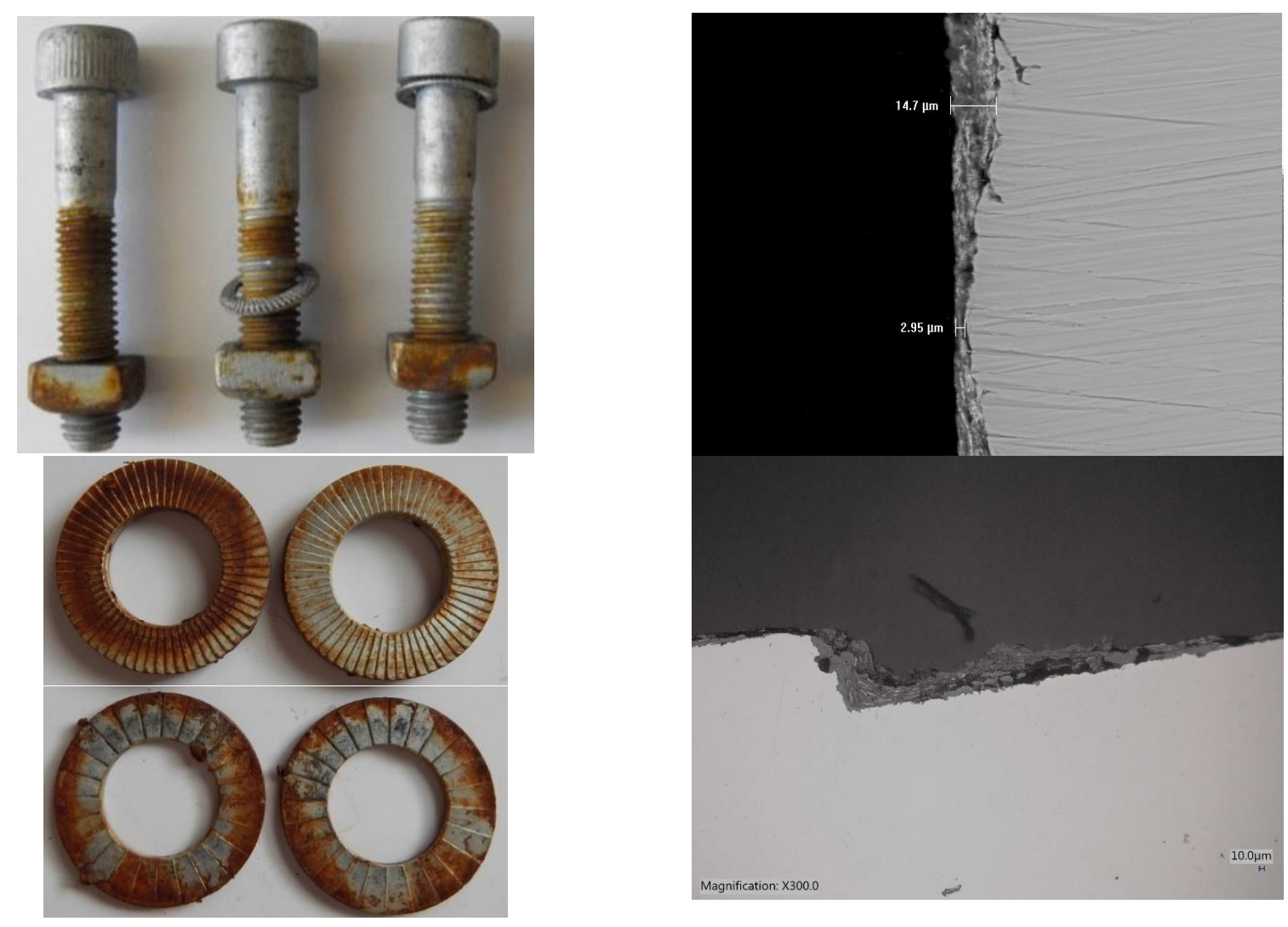

Figure 9 Corrosion attack on screws and washers after 1 year exposure

\section{ACKNOWLEDGEMENTS}

The study was performed and paper was written with support of project MPO - IP DKRVO, 2021.

\section{REFERENCES}

[1] ISHIKAWA, Shusaku, TAKAYAMA, Yasuharu. A New Sacrificial Corrosion Protection Mechanism for High Performance Zinc/Aluminum Flake Coating Systems and Applications. NASF SURFACE TECHNOLOGY WHITE PAPERS. 2014, vol. 78, no. 8, pp. 1-10.

[2] OLEKSIAK, B., KOŁTAŁO, K., POLOCZEK, R., Application methods and selected properties of zinc flake coatings. METALURGIJA. 2021, vol. 60, no. 1-2, pp. 162-164.

[3] FOUREZ, Michel, GHENO, Frederic. The Application of Zinc-Aluminium Flake Non-electroytic Surface Coatings. TRANSACTIONS OF THE IMF. 1993, vol. 71, no. 1, pp. 21-25.

[4] Coating with metallic material. Eco-friendly zinc flake surface treatment solution for preventing corrosion of metal parts and surface treatment method using same. [online]. 2016. [viewed: 2021-03-23]. Available from: https://patents.google.com/patent/WO2017164438A1/en.

[5] WYNN, Paul. Fastener Coating Developments. TRANSACTIONS OF THE IMF. 2003, vol. 81, no. 1, pp. B16-B18. 